\title{
Application of Central Composite Design in the Adsorption of Ca(II) on Metakaolin Zeolite
}

\author{
Upenyu Guyo, Lycenter Yard Phiri, and Fidelis Chigondo \\ Department of Chemical Technology, Midlands State University, Private Bag 9055, Senga, Gweru, Zimbabwe \\ Correspondence should be addressed to Fidelis Chigondo; chigondofj@gmail.com
}

Received 15 May 2017; Revised 30 June 2017; Accepted 11 July 2017; Published 10 August 2017

Academic Editor: Ana Moldes

Copyright (C) 2017 Upenyu Guyo et al. This is an open access article distributed under the Creative Commons Attribution License, which permits unrestricted use, distribution, and reproduction in any medium, provided the original work is properly cited.

\begin{abstract}
Metakaolin zeolite-A was synthesized from thermally activated kaolin clay and characterized by Fourier Transform Infrared Spectroscopy and X-Ray Diffraction Spectroscopy. The effects of pH (2-10), contact time (10-180 min), initial concentration (5-120 $\left.\mathrm{mgL}^{-1}\right)$, and dosage $(0.1-2 \mathrm{~g})$ and their interactions were investigated using response surface methodology following a central composite design. Optimum removal $(87.70 \%)$ was obtained at $\mathrm{pH} 6$, contact time $180 \mathrm{~min}$, initial concentration $40.0 \mathrm{mgL}^{-1}$, and adsorbent dosage $1.0 \mathrm{~g}$ by Excel Solver using the GRG solving method. The adsorption data fitted best to the Langmuir model with correlation coefficient $R^{2}=0.993$ and Chi-square value $\chi^{2}=4.76$. The Freundlich isotherm gave a correlation coefficient $R^{2}=0.933$ and $\chi^{2}=37.91$. The adsorption process followed the pseudo-second-order model. The calculated thermodynamic parameters showed that the adsorption process was endothermic and not thermodynamically spontaneous. The studied zeolite-A can therefore be used as a promising adsorbent for the removal of $\mathrm{Ca}$ (II) ions from aqueous solutions.
\end{abstract}

\section{Introduction}

Zeolites are crystalline, microporous, hydrated aluminosilicates formed by the sharing of oxygen atoms in the framework of aluminum and silicon tetrahedrals [1]. Synthetic zeolites are used commercially more often than natural zeolites due to the purity of their crystalline products, the uniformity of particles, the greater thermal stability, and the fact that they can be engineered with a wide variety of properties and pore sizes [2]. Zeolite synthesis involves the hydrothermal crystallization of aluminosilicate gels in the presence of alkali hydroxides [3]. The type of zeolite is affected by composition of the reaction mixture, the nature of the reactants and their pretreatments, temperature of the process, reaction time, and $\mathrm{pH}$ of the reaction mixture. The main problems in zeolite application are availability and cost of raw materials, specifically the silica source [4]. The use of commercial silica in zeolite synthesis is affected by variations in reactivity and selectivity apart from being expensive [5]. Cheaper raw materials such as clay minerals could be an alternative starting material for zeolite synthesis. Kaolin is a cheap clay mineral whose deposits are found vastly around mining areas in Zimbabwe. Many researchers have reported the synthesis of zeolites from kaolin under different conditions [6-11]. Kaolin is not stable under severe alkaline conditions and as such it is desirable to convert it into a more reactive form (metakaolin) by calcination at elevated temperatures. Because of their unique porous properties, zeolites could be applied in the removal of hardness in domestic water which is mainly due to calcium and magnesium ions. Water supplies with total hardness of more than $500 \mathrm{mg} / \mathrm{L}$ are not suitable for domestic consumption [12]. Hard water is responsible for the formation of deposits in boilers, cooling towers, water pipes, and household facilities, as well as diverse influences on the cleaning performance of detergents. Traditionally, water purification plants used lime and soda ash for the removal of hardness. One of the main drawbacks of this process is the generation of large amounts of liquid sludge as well as the need for recarbonation of the treated water [13]. The use of polyphosphates in removing water hardness is also practiced but results in massive discharge of phosphates in water bodies which lead to eutrophication [14].

Various other methods including membrane precipitation, phytoextraction, flocculation, solvent extraction, ultrafiltration, reverse osmosis, electrodialysis, and adsorption have been studied for the removal of a wide variety of cations 
from water streams including magnesium and calcium [1517]. Most of these are either inefficient or expensive and result in the generation of large amounts of sludge. Activated carbon is considered to be a particularly competitive and effective process for the removal of cations but has been hampered by the high costs associated with production and regeneration of spent carbon. The use of low-cost ion exchangers such as zeolites is an attractive method for the removal of metals from aqueous solutions. In this work, we report on the synthesis of zeolite-A from Zimbabwean kaolin and its application in the sorption of calcium ions from aqueous solutions. All the process independent variables have been optimized collectively by applying response surface methodology (RSM), a mathematical statistical technique which optimizes the process and evaluates the relationship between a set of independent variables [18-20]. Moreover, it evaluates the relative significance of the various independent variables even in the presence of complex factor-factor interactions [21]. The adsorbent was characterized using Fourier Transform Infrared (FTIR) Spectroscopy and XRD (X-Ray Diffraction) Spectroscopy.

\section{Materials and Methods}

2.1. Chemicals and Solutions. All chemicals used in this work were obtained from Skylabs (Zimbabwe) and were used as received without further purification. A pH meter (Az8601, China) was employed for $\mathrm{pH}$ measurement and $0.1 \mathrm{M}$ $\mathrm{HCl}$ and $0.1 \mathrm{M} \mathrm{NaOH}$ were used for $\mathrm{pH}$ adjustment. $\mathrm{CaCl}_{2}$ was used for the preparation of stock solution using double deionized water. All glassware used was soaked in $10 \%(\mathrm{v} / \mathrm{v})$ nitric acid solution for $24 \mathrm{~h}$ and cleaned repeatedly with double deionized water.

2.2. Sample Collection and Pretreatment. The kaolin clay used in this study was collected from Chegutu, Zimbabwe. The kaolin clay sample was pulverized and sieved through a $90 \mu \mathrm{m}$ sieve. The pulverized kaolin clay material was digested in $6 \mathrm{M} \mathrm{HCl}$ to remove iron and washed with distilled water followed by drying overnight at $120^{\circ} \mathrm{C}$. The treated kaolin clay was exposed to $900^{\circ} \mathrm{C}$ for $1 \mathrm{~h}$ where its structure was destroyed [22]. This removed all incorporated hydrocarbons and was dehydroxylated to form an activated amorphous material called metakaolin, a material which accepts and readily exchanges sodium as a guest in its structure.

\subsection{Zeolitization Using the Hydrothermal Transformation} Method. The zeolite gel was prepared by dissolving metakaolin in sodium hydroxide solutions [23]. Metakaolin $(20 \mathrm{~g})$ was refluxed and stirred in $100 \mathrm{~mL}$ of sodium hydroxide $(1,3$, and $5 \mathrm{M})$ at a temperature of $100^{\circ} \mathrm{C}$ at specified reaction times $(1,2$, and $4 \mathrm{~h})$ [5]. The metakaolin-sodium hydroxide slurries were filtered by suction filtration and washed several times with deionized water to remove excess unreacted sodium hydroxide. The reaction products were dried at a temperature of $120^{\circ} \mathrm{C}$ in the oven for $24 \mathrm{~h}$. Triplicate samples were prepared for each $\mathrm{NaOH}$ concentration and reaction time.
2.4. Characterization of the Zeolites. The Fourier Transform Infrared (FTIR) Spectroscopy spectra of the metakaolin zeolite (MZ) were obtained using a Thermo Fisher Scientific spectrometer (Nicolet 6700, USA) in the scanning range $4000-400 \mathrm{~cm}^{-1}$. A Bruker D8 Advance X-ray diffractometer (Germany) using nickel filtered $\mathrm{Cu} \mathrm{K} \alpha$ radiation $(40 \mathrm{kV}$, $40 \mathrm{~mA}$ ) was used for identification of the structural phases.

2.5. Adsorption Batch Studies. All experiments were carried out in batch mode in $250 \mathrm{~mL}$ conical flasks. Several experimental parameters (solution $\mathrm{pH}$ : $2-10$; contact time: 10-180 $\mathrm{min}$; adsorbent dosage: $0.1-2.0 \mathrm{~g}$; and initial metal ion concentration: 5-120 mg/L) were investigated following a central composite design (CCD). A predetermined adsorbent mass was added to $100 \mathrm{~mL}$ solution in a conical flask containing $\mathrm{Ca}^{2+}$ cations at a concentration according to CCD. The mixture was agitated on a shaker at $150 \mathrm{rpm}$ for a specified time at room temperature. After agitation, the solid matrix was separated from the rest of the solution by filtration using Whatman number 42 filter paper followed by centrifugation to get the supernatant solution. The determination of $\mathrm{Ca}^{2+}$ ions in aqueous solution was done by complexometric titration using standardized $0.1 \mathrm{M}$ EDTA (ethylenediaminetetraacetic acid) in the presence of Eriochrome Black T as an indicator. Typically, $100 \mathrm{~mL}$ of each supernatant solution was pipetted into a $250 \mathrm{~mL}$ conical flask, $4 \mathrm{~mL}$ of $1.0 \mathrm{M} \mathrm{NH}_{3}$ solution and 2-3 drops of Eriochrome Black T were added, and the mixture was titrated with $0.1 \mathrm{M}$ EDTA solution until the color changed from pink to blue [12].

The percentage removal $(R)$ of $\mathrm{Ca}(\mathrm{II})$ ions from aqueous solutions was determined using the following equation:

$$
R=\frac{\left(C_{o}-C_{e}\right)}{C_{o}} \times 100 \% .
$$

The equilibrium adsorption amount $\left(q_{e}\right)$ was calculated according to the mass balance equation:

$$
q_{e}=\frac{\left(C_{o}-C_{e}\right) V}{M}
$$

where $q_{e}$ is the equilibrium amount $\left(\mathrm{mg} \mathrm{g}^{-1}\right)$ of $\mathrm{Ca}(\mathrm{II})$ ions adsorbed per gram of metakaolin zeolite adsorbent, $C_{o}$ and $C_{e}$ are the $\mathrm{Ca}(\mathrm{II})$ concentrations $\left(\mathrm{mgL}^{-1}\right)$ in the solution initially and after adsorption, respectively, $V$ is the volume $(L)$ of the solution, and $M$ is the mass ( $\mathrm{g}$ ) of the adsorbent used in the experiment.

The experimental domain used is presented in Table 1. Preliminary experiments were done to obtain the extreme levels of the independent input variables. Design Expert Version 5 (Stat-Ease, USA) was used to generate the CCD experiments, optimize the levels of the independent variables, and evaluate the interactions of the process parameters. In generating the $\mathrm{CCD}$, the experimental domain for independent factors for high and low was entered in terms of alpha value of 2 to give 30 experiments with 6 center points. The percentage removal of $\mathrm{Ca}(\mathrm{II})$ ions was taken as the dependent variable. The Design Expert software was also 
TABLE 1: Experimental domain.

\begin{tabular}{lcccc}
\hline & $\mathrm{pH}$ & $\begin{array}{c}\text { Contact time } \\
(\mathrm{min})\end{array}$ & $\begin{array}{c}\text { Initial concentration } \\
\left(\mathrm{mg} \mathrm{L}^{-1}\right)\end{array}$ & $\begin{array}{c}\text { Dosage } \\
(\mathrm{g})\end{array}$ \\
\hline Min. point & 2 & 10 & 5 & 0.1 \\
Max. point & 10 & 180 & 120 & 2 \\
\hline
\end{tabular}

used for statistical, regression, and graphical analysis of the obtained data. The general Logit $R$ transformation quadratic model was proposed to be

$$
\begin{aligned}
\operatorname{Logit} R= & b_{0}+b_{1} A+b_{2} B+b_{3} C+b_{4} D+b_{5} A^{2}+b_{6} B^{2} \\
& +b_{7} C^{2}+b_{8} D^{2}+b_{9} A B+b_{10} A C+b_{11} A D \\
& +b_{12} B C+b_{13} B D+b_{14} C D
\end{aligned}
$$

where $R$ is the percentage removal of $\mathrm{Ca}(\mathrm{II})$ ions, $A$ is the $\mathrm{pH}$, $B$ is the contact time in min, $C$ is the initial concentration in $\mathrm{mg} / \mathrm{L}$, and $D$ is the dosage in $\mathrm{g}$. The optimum values of the independent input variables were obtained by Excel Solver software applying the GRG function.

2.6. Desorption Studies. $0.2 \mathrm{~g}$ of the adsorbent was left in contact with $100 \mathrm{~mL}$ of $30 \mathrm{mg} / \mathrm{L}$ of $\mathrm{Ca}(\mathrm{II})$ for $180 \mathrm{~min}$ at $150 \mathrm{rpm}$. The spent adsorbent was filtered, washed, and dried at $55^{\circ} \mathrm{C}$ for $24 \mathrm{~h}$. The dried spent adsorbent was left in contact with different concentrations of $\mathrm{NaOH}(0.1,0.5,1.0$, and $2.0 \mathrm{M}$ ) for $500 \mathrm{~min}$ and then filtered and washed several times with deionized water. The desorbed adsorbent was used for adsorption of the $\mathrm{Ca}(\mathrm{II})$ ions and the regeneration percentage was determined.

\section{Results and Discussion}

\subsection{Characterization of the Adsorbent}

3.1.1. FTIR. Zeolites were synthesized at different reaction times and different $\mathrm{NaOH}$ concentrations and the zeolite that was similar to zeolite-A was selected for use. Figure 1 shows the FTIR spectra of the metakaolin zeolites synthesized at an optimum time of $4 \mathrm{~h}$ at different $\mathrm{NaOH}$ concentrations. The spectrum of the selected zeolite (C2, Figure 1) had a band at $3458.53 \mathrm{~cm}^{-1}$ corresponding to $\mathrm{O}-\mathrm{H}$ vibration. There was structural T-O stretching and deformation at $1642.33 \mathrm{~cm}^{-1}$ and a peak at $1021.10 \mathrm{~cm}^{-1}$ that corresponded to internal tetrahedron asymmetrical vibration. A peak at $1421.37 \mathrm{~cm}^{-1}$ might be due to $\mathrm{Si}-\mathrm{O}$ asymmetric stretching whilst bands at 723.79 and $1072.79 \mathrm{~cm}^{-1}$ were due to internal symmetrical stretching vibration of (Al-Si)-O. The $473.46 \mathrm{~cm}^{-1}$ band was due to internal vibration of (Al-Si)-O bending and the $558.95 \mathrm{~cm}^{-1}$ band corresponded to the formation of double four-membered rings by external linkages [5]. The zeoliteA framework possesses good exchange capacity, making it a good material as an ion exchange agent. It may thus be concluded that IR spectra of the C2 spectra are closely complementary to zeolite-A; therefore, the C2 zeolites were used for batch adsorption studies.

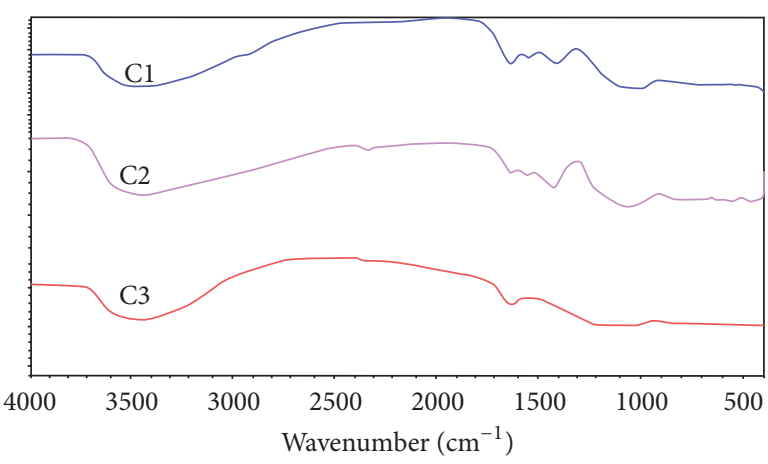

FIgURE 1: FTIR spectra of metakaolin zeolites $(\mathrm{Cl}, 4 \mathrm{~h}, 3 \mathrm{M} \mathrm{NaOH}$ zeolite; C2, 4 h, $5 \mathrm{M} \mathrm{NaOH}$ zeolite; and C3, 4 h, $1 \mathrm{M} \mathrm{NaOH}$ zeolite).

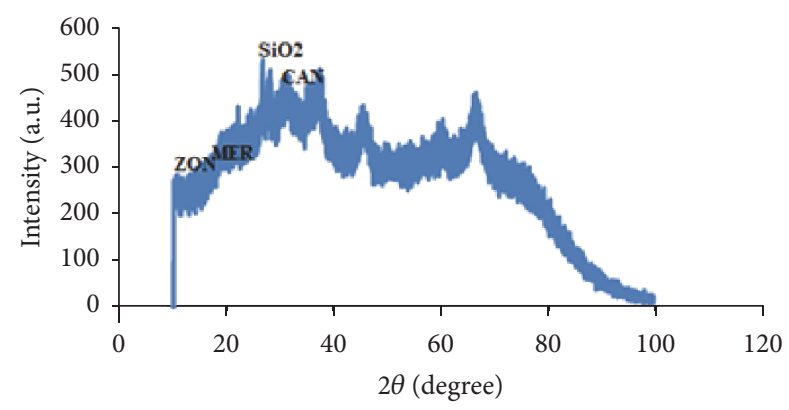

FIgURE 2: XRD pattern for metakaolin zeolite-A.

3.1.2. XRD Analysis. The XRD data (Figure 2) showed four crystallographic phases at $2 \theta$ degree values of 10.09 (ZON), and 12.69 (MER), 26.69 (Quartz), and 30.28 (CAN) are quite consistent with the two theta values of zeolite-A (LTA) showing that the pure phase of crystalline zeolite-A was produced.

3.2. Adsorption Batch Studies. Adsorption studies using MZ were done on an aqueous $\mathrm{Ca}$ (II) solution applying a central composite design [24] developed from the experimental domain presented in Table 1 . The investigation was carried out following a full central composite design consisting of 30 experiments, which included several replicate experiments to check for consistency of the adsorption procedure. The average $\mathrm{Ca}(\mathrm{II})$ removal from aqueous solutions using the prepared adsorbent over six replicate runs (midpoint experimental conditions) was $39.73 \pm 0.41 \%$ (at $95 \%$ confidence). The results obtained were consistent as evidenced by the small relative standard deviation (1.04\%). The CCD batch method was therefore capable of providing consistent results and hence was suitable for use in the investigation of the adsorption of $\mathrm{Ca}(\mathrm{II})$ ions onto MZ.

3.2.1. Response Surface Methodology Modeling. The experimental variable settings used for this investigation together with the actual experimental results are presented in Table 2.

The proposed full Logit $R$ transformation model (see (3)) was fitted on the experimental data obtained in Table 2. The least squares regression results for the adsorption of $\mathrm{Ca}$ (II) 
TABLE 2: Experimental variables and results.

\begin{tabular}{|c|c|c|c|c|c|}
\hline Run & $A: \mathrm{pH}$ & $\begin{array}{c}B \text { : contact time } \\
(\min )\end{array}$ & $\begin{array}{c}C \text { : initial concentration } \\
\left(\mathrm{mgL}^{-1}\right)\end{array}$ & $\begin{array}{c}D: \text { dosage } \\
(\mathrm{g})\end{array}$ & $\begin{array}{c}\mathrm{Ca}(\mathrm{II}) \text { removal } \\
(\%)\end{array}$ \\
\hline 1 & 2 & 95 & 62.5 & 1.05 & 32.0 \\
\hline 2 & 4 & 52.5 & 33.75 & 0.575 & 57.8 \\
\hline 3 & 4 & 52.5 & 33.75 & 1.525 & 62.2 \\
\hline 4 & 4 & 52.5 & 91.25 & 1.525 & 26.8 \\
\hline 5 & 4 & 52.5 & 91.25 & 0.575 & 24.7 \\
\hline 7 & 4 & 137.5 & 33.75 & 0.575 & 74.1 \\
\hline 8 & 4 & 137.5 & 33.75 & 1.525 & 78.5 \\
\hline 9 & 4 & 137.5 & 91.25 & 1.525 & 28.5 \\
\hline 10 & 4 & 137.5 & 91.25 & 0.575 & 25.8 \\
\hline 11 & 6 & 10 & 62.5 & 1.05 & 36.0 \\
\hline 12 & 6 & 95 & 62.5 & 1.05 & 39.2 \\
\hline 13 & 6 & 95 & 62.5 & 1.05 & 39.2 \\
\hline 14 & 6 & 95 & 62.5 & 1.05 & 40.0 \\
\hline 15 & 6 & 95 & 62.5 & 2 & 42.4 \\
\hline 16 & 6 & 95 & 62.5 & 1.05 & 40.0 \\
\hline 17 & 6 & 95 & 62.5 & 0.1 & 36.0 \\
\hline 18 & 6 & 95 & 62.5 & 1.05 & 40.0 \\
\hline 19 & 6 & 95 & 62.5 & 1.05 & 40.0 \\
\hline 20 & 6 & 95 & 120 & 1.05 & 22.9 \\
\hline 21 & 6 & 180 & 62.5 & 1.05 & 43.2 \\
\hline 22 & 8 & 52.5 & 33.75 & 0.575 & 66.7 \\
\hline 23 & 8 & 52.5 & 33.75 & 1.525 & 72.6 \\
\hline 24 & 8 & 52.5 & 91.25 & 1.525 & 30.1 \\
\hline 25 & 8 & 52.5 & 91.25 & 0.575 & 26.8 \\
\hline 26 & 8 & 137.5 & 33.75 & 1.525 & 75.6 \\
\hline 27 & 8 & 137.5 & 33.75 & 0.575 & 59.3 \\
\hline 28 & 8 & 137.5 & 91.25 & 1.525 & 34.5 \\
\hline 29 & 8 & 137.5 & 91.25 & 0.575 & 32.3 \\
\hline 30 & 10 & 95 & 62.5 & 1.05 & 47.2 \\
\hline
\end{tabular}

TABLE 3: Least squares regression data for $\mathrm{Ca}(\mathrm{II})$ removal.

\begin{tabular}{|c|c|c|c|c|c|c|}
\hline Factor & Coefficient estimate & $\mathrm{DF}$ & Standard error & $\begin{array}{c}t \text { for } H_{0} \\
\text { Coeff. }=0\end{array}$ & Prob $>|t|$ & VIF \\
\hline Intercept & 2.16972 & 1 & 0.2366 & & & \\
\hline$A: \mathrm{pH}$ & 0.062119 & 1 & 0.0110 & 5.64648 & $<0.0001$ & 1.01478 \\
\hline$B$ : contact time & 0.008357 & 1 & 0.0015 & 5.48405 & $<0.0001$ & 8.79209 \\
\hline$C$ : concentration & -0.0863 & 1 & 0.0065 & -13.279 & $<0.0001$ & 47.681 \\
\hline$D$ : dosage & 0.149761 & 1 & 0.0463 & 3.23304 & 0.0042 & 1.01478 \\
\hline$C^{2}$ & 0.0005 & 1 & 0.0000 & 10.147 & $<0.0001$ & 44.4523 \\
\hline$B C$ & $-8.10 E-05$ & 1 & 0.0000 & -3.6024 & 0.0018 & 14.1953 \\
\hline$R^{2}$ & 0.984 & & & & & \\
\hline
\end{tabular}

after elimination of the insignificant terms $(p>0.05)$ during stepwise multiple regression are summarized in Table 3.

All the $p$ values associated with the coefficients of $\mathrm{pH}(A)$, contact time $(B)$, initial concentration $(C)$, dosage concentration $(D)$, initial concentration squared term $\left(C^{2}\right)$, and the interaction between contact time and initial concentration term $(B C)$ were smaller than 0.05 (Table 3), indicating a significant effect of these factors on the percentage removal of calcium by metakaolin zeolite. The interaction between contact time and initial concentration $(B C)$ has an antagonistic 
TABLE 4: Results for ANOVA for the model.

\begin{tabular}{lcccc}
\hline Source & Sum of squares & DF & Mean square & $F$-value \\
\hline Model & 13.4078 & 6 & 2.23463 & 203.981 \\
Residual & 0.219102 & 20 & 0.010955 & 48.6273 \\
Lack of fit & 0.21761 & 15 & 0.014507 & 0.0002 \\
Pure error & 0.001492 & 5 & 0.000298 & \\
Cor. total & 13.6269 & 26 & & \\
\hline
\end{tabular}

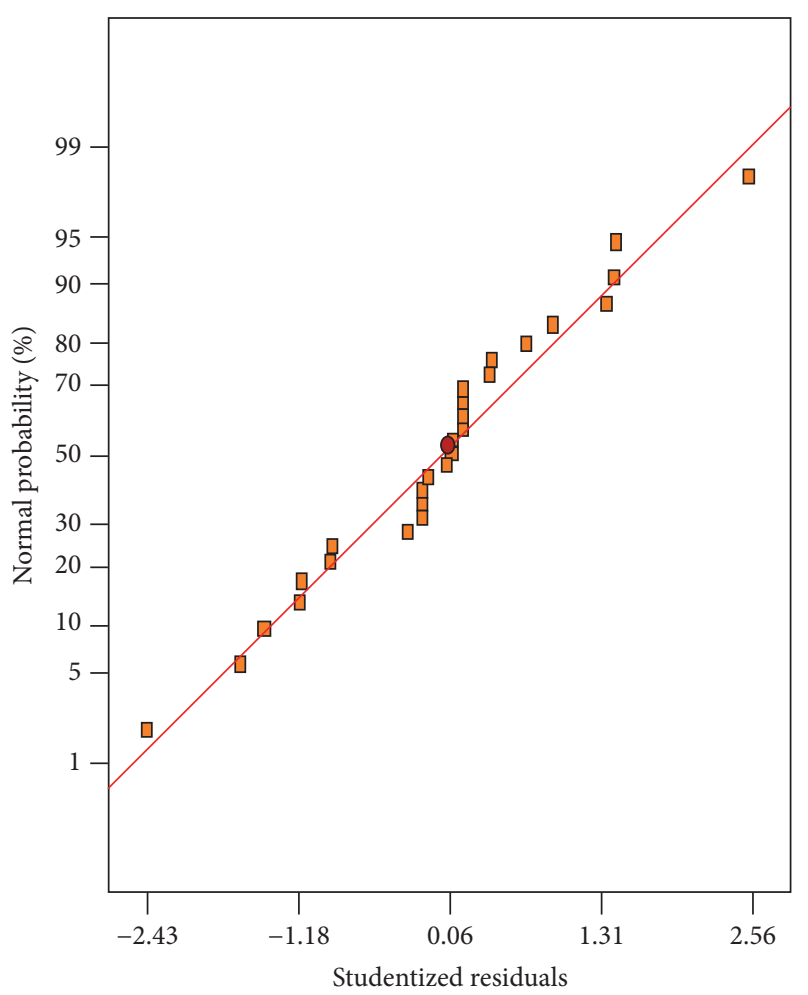

FIGURE 3: Normal plot of residuals.

effect on the removal of calcium as shown by the negative value of the associated coefficient. The final model obtained after elimination of the insignificant term was

$$
\text { Logit } R=b_{0}+b_{1} A+b_{2} B+b_{3} C+b_{4} D+b_{5} C^{2}+b_{6} B C \text {. }
$$

The results of the analysis of variance for the regression model are presented in Table 4.

The $p$ value for the model was less than 0.05 ( $p<$ 0.0001 ), indicating that the model was statistically significant. Moreover, a higher regression coefficient $\left(R^{2}=0.984\right)$ supported the significance of the model [25]. Model validity was evaluated by normal probability plot which was produced by the Design Expert software. Figure 3 shows that the residuals were close to the straight line and were scattered randomly around it with no particular pattern, showing no abnormal behavior [26].

The plot of standard residuals versus predicted values showed a random distribution of residuals (difference between the experimental and the predicted values), with no particular pattern showing well behaved residuals

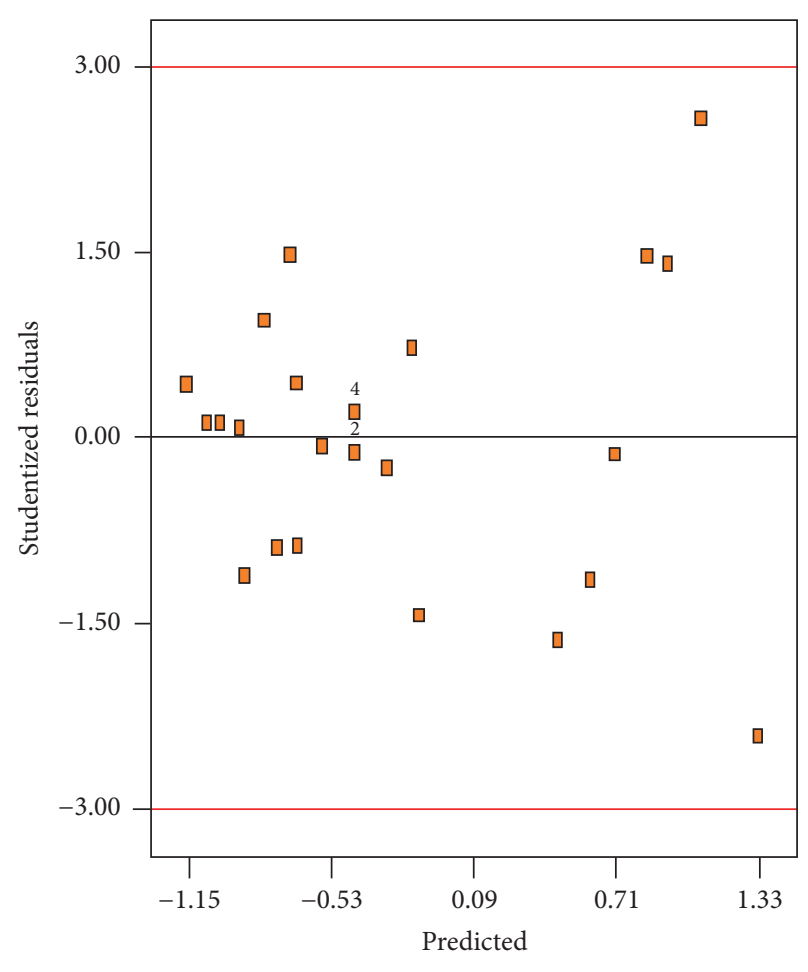

FIGURE 4: Plot of standard residuals versus predicted values.

(Figure 4) [27]. Moreover, it showed no outliers supporting the statistical validity of the model.

3.2.2. Model Interpretation. A 3-dimensional surface plot gives vital information on the behavior of the experimental design system. This aids the evaluation of the effects of the independent variables on the response factor. Figure 5 shows the effect of $\mathrm{pH}$ and contact time on \% removal of $\mathrm{Ca}$ (II) ions at constant dosage amount and initial $\mathrm{Ca}(\mathrm{II})$ concentration. An increase in both $\mathrm{pH}$ and contact time increased the percentage removal of $\mathrm{Ca}$ (II). Since the sorbent had abundant binding sites, the gradual occupancy of these sites over different times resulted in an increase in the uptake of $\mathrm{Ca}(\mathrm{II})$. The lower percentage removal observed in acidic $\mathrm{pH}$ medium is due to protonation of adsorbent functional groups or competition of $\mathrm{H}^{+}$with $\mathrm{Ca}$ (II) ions to bind and occupy the active sites of the adsorbent. On the other hand, higher $\mathrm{pH}$ medium promotes formation of insoluble metal hydroxides such as $\mathrm{Ca}(\mathrm{OH})_{2}$ which are filtered off.

The linear increase in adsorption efficiency of MZ with increasing adsorbent dosage indicated the accessibility of a 


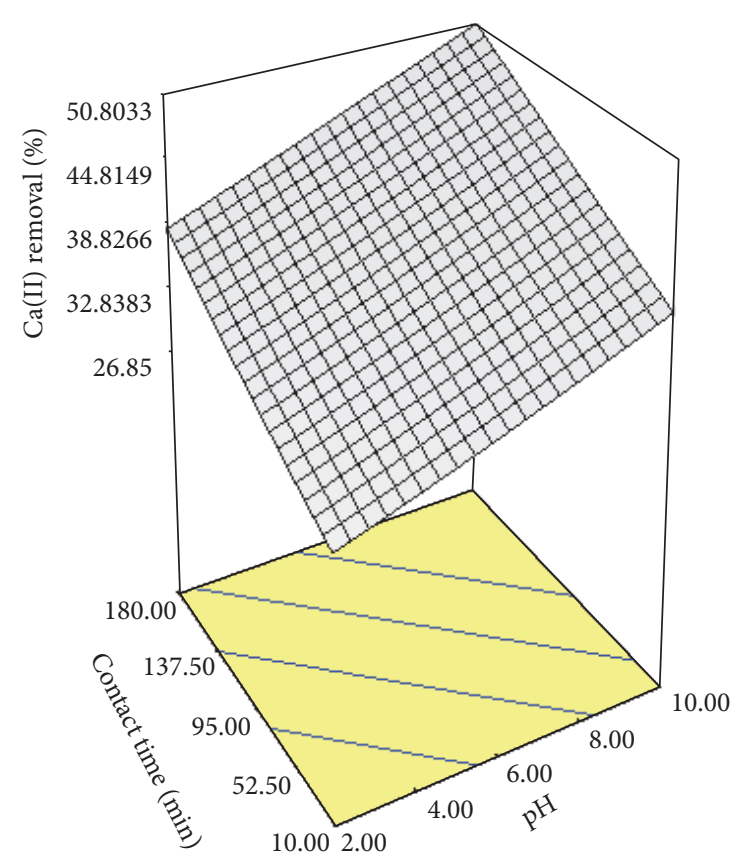

FIgURE 5: 3D surface plot for total hardness removal.

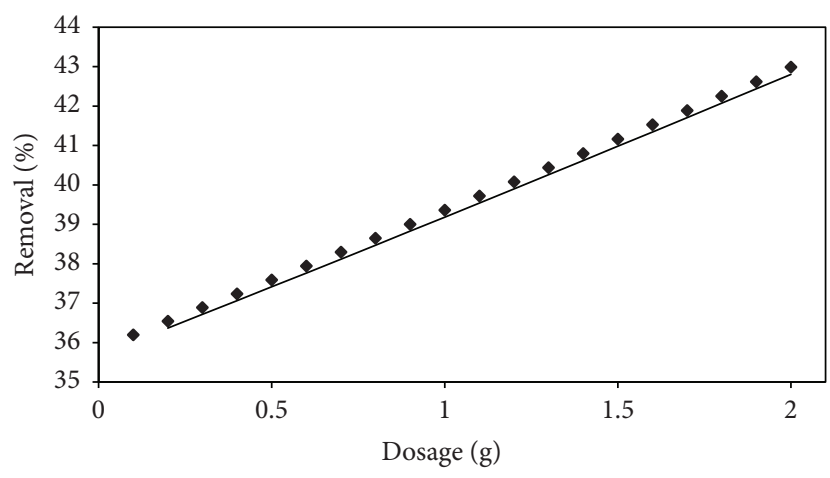

Figure 6: Effect of adsorbent dosage.

larger number of sorption sites at higher dosage to adsorb $\mathrm{Ca}$ (II) ions (Figure 6).

The effect of initial metal concentration on the removal efficiency of the zeolite adsorbent is illustrated in Figure 7. The initial concentration-profile plot shows a remarkable decrease in removal efficiency as initial concentration is increased. At low concentration, most of the metal ions in the solution interact with active sites on the adsorbent, resulting in high percentage removal [28].

3.2.3. Effect of Temperature. The amount of $\mathrm{Ca}(\mathrm{II})$ adsorbed on $\mathrm{MZ}$ as a function of solution temperature is shown in Figure 8. The removal efficiency decreased as temperature was increased from 20 to $40^{\circ} \mathrm{C}$, showing that low temperature favors $\mathrm{Ca}(\mathrm{II})$ removal from aqueous solutions. The decrease of $\mathrm{Ca}$ (II) removal may be attributed to the $\mathrm{Ca}$ (II) ions escaping from the solid phase with the rise in temperature of solutions [29]. The optimum temperature of $20^{\circ} \mathrm{C}$ was used for all further experiments.

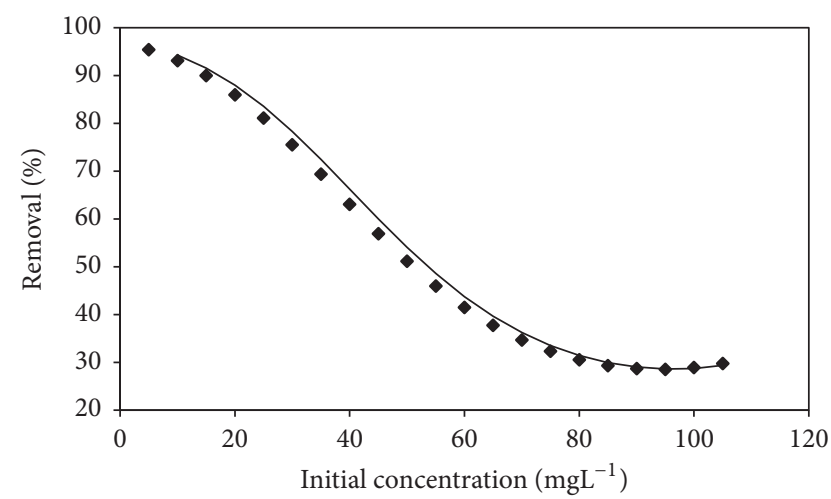

FIGURE 7: Effect of initial concentration.

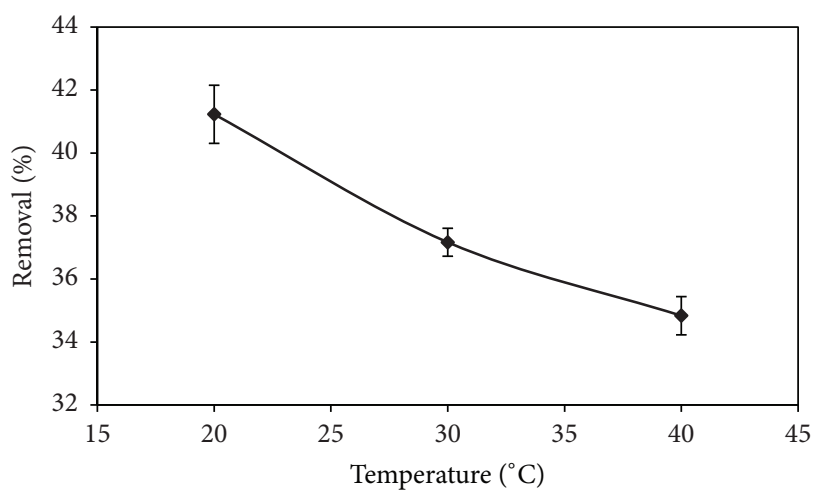

Figure 8: Effect of temperature.

3.2.4. Adsorption Thermodynamics. Thermodynamic parameters such as standard Gibb's free energy change $\left(\Delta G^{o}\right)$, the entropy change $\left(\Delta S^{o}\right)$, and the enthalpy change $\left(\Delta H^{o}\right)$ were calculated from the following equations:

$$
\begin{aligned}
\Delta G^{o} & =-R T \ln K_{d}, \\
K_{d} & =\frac{q_{e}}{C_{e}}, \\
\Delta G^{o} & =\Delta H^{o}-T \Delta S^{o}, \\
\ln K_{d} & =\frac{\Delta S^{o}}{R}+\frac{\Delta H^{o}}{R T},
\end{aligned}
$$

where $R$ is the ideal gas constant, $T$ is the temperature in $\mathrm{K}$, and $K_{d}$ is the thermodynamic equilibrium constant. The parameter $q_{e}$ is the amount of $\mathrm{Ca}(\mathrm{II})$ adsorbed at equilibrium in $\mathrm{mg} / \mathrm{L}$ and $C_{e}$ is the equilibrium concentration of $\mathrm{Ca}(\mathrm{II})$ ions in the solution. The intercept and the slope of the Van't Hoff plots of $\ln K_{d}$ versus $1 / T$ were used to determine the $\Delta S^{o}$ and $\Delta H^{o}$ values, respectively. Table 5 shows the thermodynamic parameters. The calculated $\Delta H^{o}$ value was positive, showing that the adsorption process was endothermic. A slightly positive $\Delta S^{o}$ indicated some randomness at the solid/liquid interface during the sorption process. The $\Delta G^{o}$ values were all positive, showing that the sorption of metals was not thermodynamically spontaneous. 
TABLE 5: Thermodynamic parameters.

\begin{tabular}{lccc}
\hline Temperature $(\mathrm{K})$ & $\Delta G^{o}\left(\mathrm{kJmol}^{-1}\right)$ & $\Delta H^{o}\left(\mathrm{kJmol}^{-1}\right)$ & $\Delta S^{o}\left(\mathrm{kJmol}^{-1}\right)$ \\
\hline 293.15 & +1.284 & +3.953 & +0.0091 \\
303.15 & +1.193 & & \\
313.15 & +1.102 & & \\
\hline
\end{tabular}

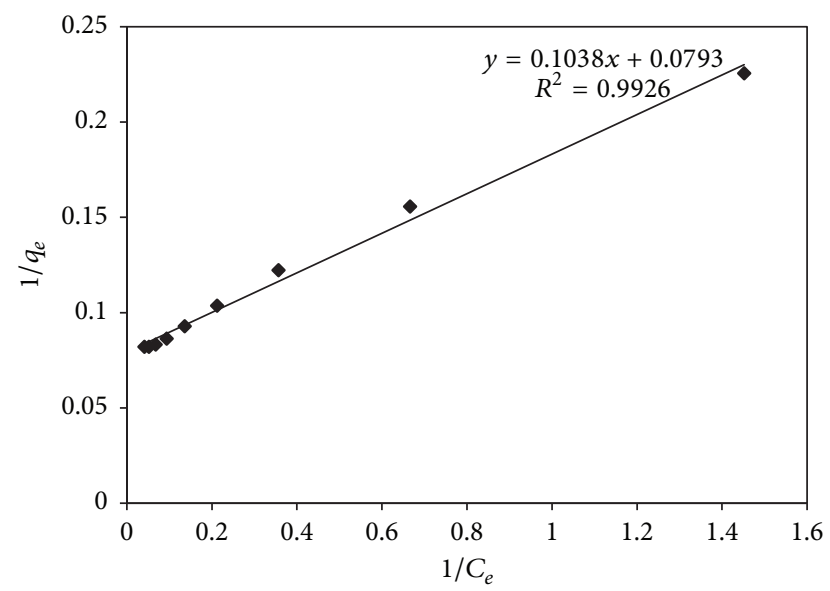

FIGURE 9: Langmuir isotherm model.

3.2.5. Adsorption Isotherms. Adsorption isotherms are useful in determining the nature of the interaction between the adsorbate and the adsorbent. In this study, the Freundlich [30] and Langmuir [31] adsorption isotherms were used to interpret the experimental data.

The linearized form of the Langmuir isotherm model can be represented by

$$
\frac{1}{q_{e}}=\frac{1}{q_{\max }}+\left(\frac{1}{b q_{\max }}\right) \frac{1}{C_{e}},
$$

where $q_{e}$ is the amount of metal ion adsorbed at equilibrium, $q_{\max }$ is the maximum adsorption capacity $\left(\mathrm{mg} \mathrm{g}^{-1}\right)$, $C_{e}\left(\mathrm{mgL}^{-1}\right)$ is the equilibrium concentration, and $b$ is the equilibrium Langmuir constant. A plot of $1 / q_{e}$ versus $1 / C_{e}$ (Figure 9) gave a straight line with $1 / q_{\max }$ as intercept and $1 / b q_{\max }$ as slope, and hence $q_{\max }$ and $b$ could be estimated (Table 6).

Monolayer sorption with a heterogeneous energetic distribution of active sites, coupled by interaction between the adsorbed molecules, is assumed by the Freundlich isotherm. The linearized Freundlich isotherm equation is given by

$$
\ln q_{e}=\ln K_{F}+\frac{1}{n} \ln C_{e},
$$

where $q_{e}\left(\mathrm{mgg}^{-1}\right)$ is the amount of metal ion adsorbed at equilibrium by the adsorbent, $K_{F}\left(\mathrm{mgg}^{-1}\right)$ and $n$ are constants representing the adsorption capacity and intensity of adsorption, respectively, and $C_{e}\left(\mathrm{mgL}^{-1}\right)$ is the equilibrium concentration. A plot of $\ln q_{e}$ versus $\ln C_{e}$ (Figure 10) gave a straight line, and $K_{F}$ and $n$ were estimated from the intercept and slope, respectively (Table 6). The calculated values of $n$
TABLE 6: Equilibrium studies parameters.

\begin{tabular}{lcc}
\hline Isotherm & Parameter & Value \\
\hline \multirow{4}{*}{ Langmuir } & $q_{\max }\left(\mathrm{mg} \mathrm{g}^{-1}\right)$ & 12.610 \\
& $b\left(\mathrm{~L} \mathrm{mg}^{-1}\right)$ & 0.764 \\
& $\chi^{2}$ & 4.76 \\
$R^{2}$ & 0.993 \\
\hline \multirow{4}{*}{ Freundlich } & $K F\left(\mathrm{mg} \mathrm{g}^{-1}\right)$ & 5.608 \\
& $n$ & 3.578 \\
& $\chi^{2}$ & 37.91 \\
$R^{2}$ & 0.933 \\
\hline
\end{tabular}

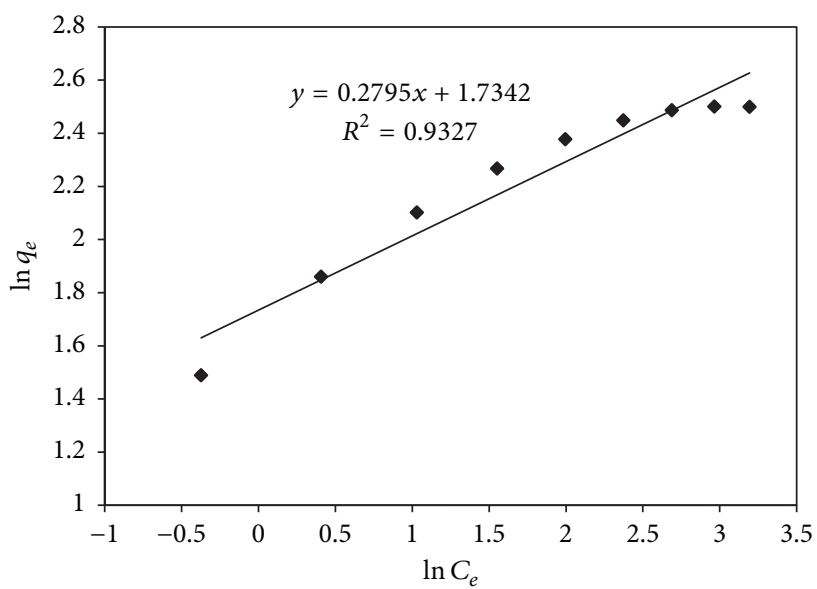

FIGURE 10: Freundlich isotherm model.

(3.578) were between 1 and 10 indicating favorability of the adsorption of $\mathrm{Ca}$ (II) ions on the adsorbent.

The Langmuir isotherm model correlation coefficient $\left(R^{2}=0.993\right)$ was significantly closer to unity relative to that of the Freundlich isotherm model $\left(R^{2}=0.933\right)$. Moreover, the Chi-square value for the Langmuir model $\left(\chi^{2}=4.76\right)$ was lower than that of Freundlich model $\left(\chi^{2}=37.91\right)$, indicating that the Freundlich model could not fit all the experimental data well.

3.2.6. Adsorption Kinetics. In the current study, the pseudofirst-order and pseudo-second-order models were used for determining the mechanism of the adsorption process. The pseudo-first-order model which assumes that the rate of adsorption site occupation is proportional to the number of unoccupied sites is expressed by the Lagergren equation [32] (Lagergren, 1898) in the linear form as follows:

$$
\log \left(q_{e}-q_{t}\right)=\log q_{e}-\frac{t \cdot k_{1}}{2.3}
$$

where $q_{e}$ and $q_{t}$ are the amount of $\mathrm{Ca}(\mathrm{II})$ adsorbed $\left(\mathrm{mg} \mathrm{g}^{-1}\right)$ onto $\mathrm{MZ}$ at equilibrium and at any time $t$, respectively, $k_{1}$ $\left(\mathrm{min}^{-1}\right)$ is the rate constant of pseudo-first-order model, and $t$ is the time (min). A plot of $\log \left(q_{e}-q_{t}\right)$ versus $t$ (Figure 11) was used to estimate the values of $k_{1}$ and $q_{e}$ from the slope and the intercept, respectively. 
TABLE 7: Kinetic parameters.

\begin{tabular}{lccccr}
\hline Experimental value & \multicolumn{3}{c}{ Pseudo-first-order kinetic model } & \multicolumn{3}{c}{ Pseudo-second-order kinetic model } \\
$q_{e}\left(\mathrm{mg} \mathrm{g}^{-1}\right)$ & $q_{e}\left(\mathrm{mg} \mathrm{g}^{-1}\right)$ & $k_{1}\left(\mathrm{~min}^{-1}\right)$ & $R^{2}$ & $q_{e}\left(\mathrm{mg} \mathrm{g}^{-1}\right)$ & $k_{1}\left(\mathrm{~g} \mathrm{mg}^{-1} \mathrm{~min}^{-1}\right)$ \\
\hline 2.77 & 1.01 & 0.01 & 0.964 & 2.81 & 0.0318 \\
\hline
\end{tabular}

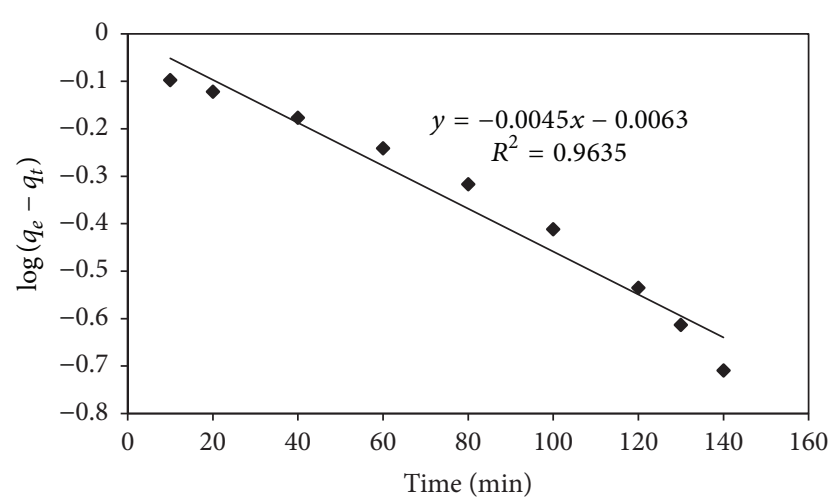

Figure 11: Pseudo-first-order model.

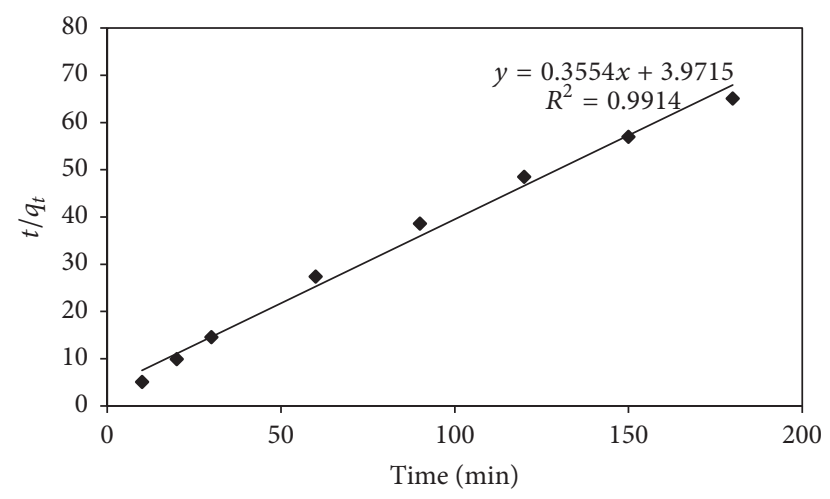

FIgURe 12: Pseudo-second-order kinetic model.

The second-order kinetic model can be expressed in the linear form as follows [33]:

$$
\frac{t}{q_{t}}=\frac{t}{q_{e}}+\frac{1}{k_{2}\left(q_{e}\right)^{2}}
$$

where $k_{2}$ is the equilibrium rate constant of pseudo-secondorder model $\left(\mathrm{g} \mathrm{mg}^{-1} \mathrm{~min}^{-1}\right)$. The values of $q_{e}$ and $k_{2}$ (Table 7) were determined from the slope and intercept of the plot of $\left(t / q_{t}\right)$ versus $t$, respectively (Figure 12$)$. The pseudo-secondorder kinetic model correlation coefficient was $R^{2}=0.991$, suggesting the applicability of the model to the adsorption of $\mathrm{Ca}(\mathrm{II})$ by MZ. Furthermore, the $q_{e, \text { cal }}$ value $\left(2.81 \mathrm{mg} \mathrm{g}^{-1}\right)$ for the pseudo-second-order kinetic reaction was found to be in better agreement with the $q_{e \text {,exp }}$ value $\left(2.77 \mathrm{mg} \mathrm{g}^{-1}\right)$.

3.2.7. Desorption Studies. The reusability of the spent adsorbent was studied by desorption/regeneration experiments, to evaluate the economical feasibility of the method. Regeneration percentage of the spent adsorbent versus $\mathrm{NaOH}$ is

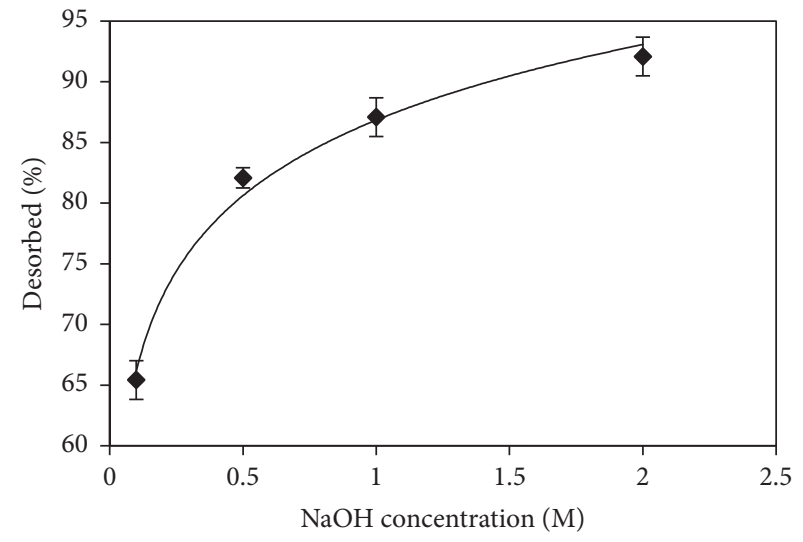

FIgURE 13: Desorption of $\mathrm{Ca}(\mathrm{II})$ ions from the spent adsorbent.

illustrated in Figure 13. Maximum recovery of the adsorbed metal ions was achieved at $2 \mathrm{M} \mathrm{NaOH}$ concentration leading to $90 \%$ desorption of the adsorbed $\mathrm{Ca}(\mathrm{II})$.

\section{Conclusions}

The present study shows that metakaolin zeolite has much potential as an adsorbent for the removal of $\mathrm{Ca}$ (II) from aqueous solutions. The influences of $\mathrm{pH}$, adsorbent dosage, contact time, and initial concentration on adsorption of the metal ion and their interactions were investigated by a response surface methodology and ANOVA. The Excel Solver showed that optimum removal $(87.70 \%)$ was obtained at a $\mathrm{pH}$, contact time, adsorbent dosage, and initial $\mathrm{Ca}(\mathrm{II})$ concentration of $6,180 \mathrm{~min}, 1.0 \mathrm{~g}$, and $40.0 \mathrm{mg} \mathrm{L}^{-1}$, respectively. Confirmatory experimental analysis under the optimized conditions gave average $\mathrm{Ca}$ (II) removal of $87.26 \pm 0.31 \%$. The adsorption process was found to be endothermic and not thermodynamically spontaneous. The Langmuir isotherm model best described the adsorption mechanism with maximum adsorption capacity of $12.61 \mathrm{mg} \mathrm{g}^{-1}$. The kinetic study was performed based on pseudo-first-order and pseudosecond-order equations and the adsorption followed pseudosecond-order kinetic model. The results obtained showed that metakaolin zeolite can be used as an effective adsorbent for removal of $\mathrm{Ca}(\mathrm{II})$ ions from aqueous solutions.

\section{Conflicts of Interest}

The authors declare that there are no conflicts of interest regarding the publication of this paper. 


\section{Acknowledgments}

The authors are grateful to the Department of Chemical Technology, Midlands State University, Gweru, Zimbabwe, for providing the research facilities.

\section{References}

[1] H. Liu, S. Peng, L. Shu, T. Chen, T. Bao, and R. L. Frost, "Magnetic zeolite $\mathrm{NaA}$ : synthesis, characterization based on metakaolin and its application for the removal of $\mathrm{Cu}^{2+}, \mathrm{Pb}^{2+}$," Chemosphere, vol. 91, no. 11, pp. 1539-1546, 2013.

[2] M. Gougazeh and J.-C. Buhl, "Synthesis and characterization of zeolite A by hydrothermal transformation of natural Jordanian kaolin," Journal of the Association of Arab Universities for Basic and Applied Sciences, vol. 15, no. 1, pp. 35-42, 2014.

[3] H. S. Ibrahim, T. S. Jamil, and E. Z. Hegazy, "Application of zeolite prepared from Egyptian kaolin for the removal of heavy metals: II. Isotherm models," Journal of Hazardous Materials, vol. 182, no. 1-3, pp. 842-847, 2010.

[4] T. T. Walek, F. Saito, and Q. Zhang, "The effect of low solid/liquid ratio on hydrothermal synthesis of zeolites from fly ash," Fuel, vol. 87, no. 15-16, pp. 3194-3199, 2008.

[5] C.-F. Wang, J.-S. Li, L.-J. Wang, and X.-Y. Sun, "Influence of $\mathrm{NaOH}$ concentrations on synthesis of pure-form zeolite A from fly ash using two-stage method," Journal of Hazardous Materials, vol. 155, no. 1-2, pp. 58-64, 2008.

[6] T. S. Jamil, H. S. Ibrahim, I. H. Abd El-Maksoud, and S. T. El-Wakeel, "Application of zeolite prepared from Egyptian kaolin for removal of heavy metals: I. Optimum conditions," Desalination, vol. 258, no. 1-3, pp. 34-40, 2010.

[7] A. A. Ismail, R. M. Mohamed, I. A. Ibrahim, G. Kini, and B. Koopman, "Synthesis, optimization and characterization of zeolite A and its ion-exchange properties," Colloids and Surfaces A: Physicochemical and Engineering Aspects, vol. 366, no. 1-3, pp. 80-87, 2010.

[8] A. R. Loiola, J. C. R. A. Andrade, J. M. Sasaki, and L. R. D. da Silva, "Structural analysis of zeolite NaA synthesized by a costeffective hydrothermal method using kaolin and its use as water softener," Journal of Colloid and Interface Science, vol. 367, no. 1, pp. 502-508, 2012.

[9] M. L. Mignoni, D. I. Petkowicz, N. R. C. Fernandes Machado, and S. B. C. Pergher, "Synthesis of mordenite using kaolin as Si and Al source," Applied Clay Science, vol. 41, no. 1-2, pp. 99-104, 2008.

[10] D. M. El-Mekkawi and M. M. Selim, "Removal of $\mathrm{Pb}^{2+}$ from water by using $\mathrm{Na}-\mathrm{Y}$ zeolites prepared from Egyptian kaolins collected from different sources," Journal of Environmental Chemical Engineering, vol. 2, no. 1, pp. 723-730, 2014.

[11] S. Chandrasekhar and P. N. Pramada, "Microwave assisted synthesis of zeolite A from metakaolin," Microporous and Mesoporous Materials, vol. 108, no. 1-3, pp. 152-161, 2008.

[12] M. N. Sepehr, M. Zarrabi, H. Kazemian, A. Amrane, K. Yaghmaian, and H. R. Ghaffari, "Removal of hardness agents, calcium and magnesium, by natural and alkaline modified pumice stones in single and binary systems," Applied Surface Science, vol. 274, pp. 295-305, 2013.

[13] A. Dimirkou and M. K. Doula, "Use of clinoptilolite and an Feoverexchanged clinoptilolite in $\mathrm{Zn}^{2+}$ and $\mathrm{Mn}^{2+}$ removal from drinking water," Desalination, vol. 224, no. 1-3, pp. 280-292, 2008 .
[14] Z. Xue, Z. Li, J. Ma et al., "Effective removal of $\mathrm{Mg}^{2+}$ and $\mathrm{Ca}^{2+}$ ions by mesoporous LTA zeolite," Desalination, vol. 341, no. 1 , pp. 10-18, 2014.

[15] L. Fu, J. Wang, and Y. Su, "Removal of low concentrations of hardness ions from aqueous solutions using electrodeionization process," Separation and Purification Technology, vol. 68, no. 3, pp. 390-396, 2009.

[16] J. N. Apell and T. H. Boyer, "Combined ion exchange treatment for removal of dissolved organic matter and hardness," Water Research, vol. 44, no. 8, pp. 2419-2430, 2010.

[17] L. Seifi, A. Torabian, H. Kazemian et al., "Adsorption of BTEX on surfactant modified granulated natural zeolite nanoparticles: parameters optimizing by applying taguchi experimental design method," Clean - Soil, Air, Water, vol. 39, no. 10, pp. 939-948, 2011.

[18] M. Roosta, M. Ghaedi, A. Daneshfar, R. Sahraei, and A. Asghari, "Optimization of the ultrasonic assisted removal of methylene blue by gold nanoparticles loaded on activated carbon using experimental design methodology," Ultrasonics Sonochemistry, vol. 21, no. 1, pp. 242-252, 2014.

[19] M. Roosta, M. Ghaedi, A. Daneshfar, and R. Sahraei, "Experimental design based response surface methodology optimization of ultrasonic assisted adsorption of safaranin $\mathrm{O}$ by tin sulfide nanoparticle loaded on activated carbon," Spectrochimica Acta - Part A: Molecular and Biomolecular Spectroscopy, vol.122, pp. 223-231, 2014.

[20] M. K. Satapathy and P. Das, "Optimization of crystal violet dye removal using novel soil-silver nanocomposite as nanoadsorbent using response surface methodology," Journal of Environmental Chemical Engineering, vol. 2, no. 1, pp. 708-714, 2014.

[21] M. Savasari, M. Emadi, M. A. Bahmanyar, and P. Biparva, "Optimization of Cd (II) removal from aqueous solution by ascorbic acid-stabilized zero valent iron nanoparticles using response surface methodology," Journal of Industrial and Engineering Chemistry, vol. 21, pp. 1403-1409, 2015.

[22] C. A. Ríos, C. D. Williams, and M. A. Fullen, "Nucleation and growth history of zeolite LTA synthesized from kaolinite by two different methods," Applied Clay Science, vol. 42, no. 3-4, pp. 446-454, 2009.

[23] P. Thuadaij and N. Nuntiya, "Synthesis of Na-x hydrate zeolite from fly ash and amorphous silica from rice husk ash by fusion with caustic soda prior to incubation," in Proceedings of the International Conference on Chemistry and Chemical Process IPCBEE, vol. 10, pp. 69-74, 2011.

[24] S. Sugashini and K. M. M. S. Begum, "Optimization using central composite design (CCD) for the biosorption of $\mathrm{Cr}(\mathrm{VI})$ ions by cross linked chitosan carbonized rice husk (CCACR)," Clean Technologies and Environmental Policy, vol. 15, no. 2, pp. 293-302, 2013.

[25] A. Fakhri, "Application of response surface methodology to optimize the process variables for fluoride ion removal using maghemite nanoparticles," Journal of Saudi Chemical Society, vol. 18, no. 4, pp. 340-347, 2014.

[26] A. C. Cameron and P. K. Trivedi, Regression analysis of count data, vol. 53 of Econometric Society Monographs, Cambridge University Press, Cambridge, England, 2nd edition, 2013.

[27] D. C. Montgomery and E. A. Peck, Introduction to Linear Regression Analysis, John Wiley \& Sons, New York, NY, USA, 1982.

[28] M. Moyo, U. Guyo, G. Mawenyiyo, N. P. Zinyama, and B. C. Nyamunda, "Marula seed husk (Sclerocarya birrea) biomass 
as a low cost biosorbent for removal of $\mathrm{Pb}$ (II) and $\mathrm{Cu}(\mathrm{II})$ from aqueous solution," Journal of Industrial and Engineering Chemistry, vol. 27, pp. 126-132, 2015.

[29] U. Guyo, J. Mhonyera, and M. Moyo, “ $\mathrm{Pb}$ (II) adsorption from aqueous solutions by raw and treated biomass of maize stovera comparative study," Process Safety and Environmental Protection, vol. 93, pp. 192-200, 2015.

[30] H. M. Freundlich, "Over the adsorption in solution," Journal of Phyical Chemisttry, vol. 57, pp. 384-470, 1906.

[31] I. Langmuir, "The adsorption of gases on plane surfaces of glass, mica and platinum," The Journal of the American Chemical Society, vol. 40, no. 9, pp. 1361-1403, 1918.

[32] S. Lagergren, "About the theory of so-called adsorption of soluble substances," Kungliga Svenska Vetenskapsakademiens Handlingar, vol. 24, pp. 1-39, 1898.

[33] Y. S. Ho and G. McKay, "Pseudo-second order model for sorption processes," Process Biochemistry, vol. 34, no. 5, pp. 451-465, 1999. 

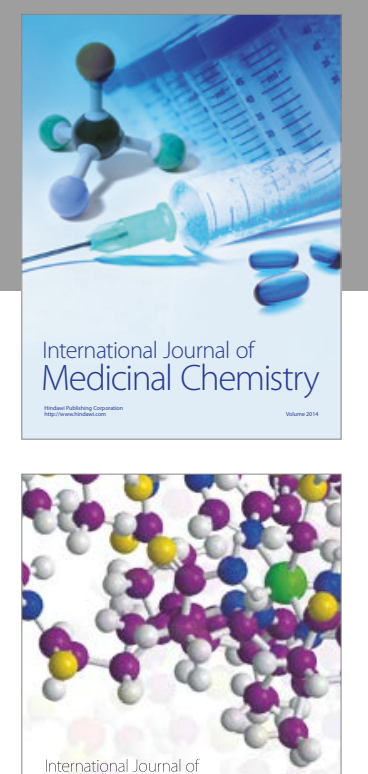

Carbohydrate Chemistry

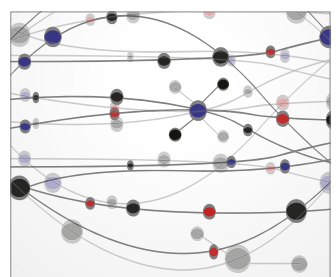

The Scientific World Journal
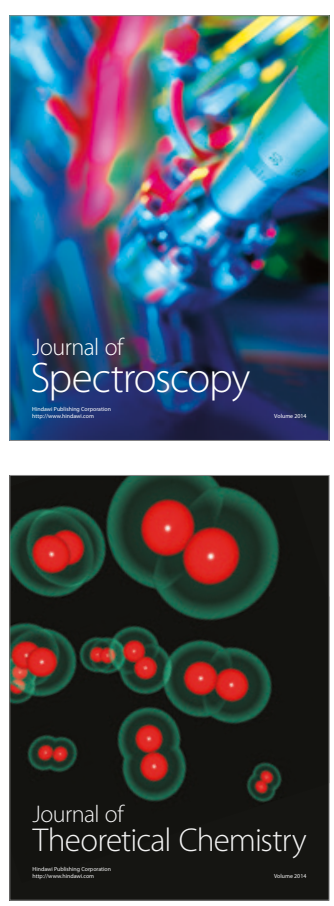
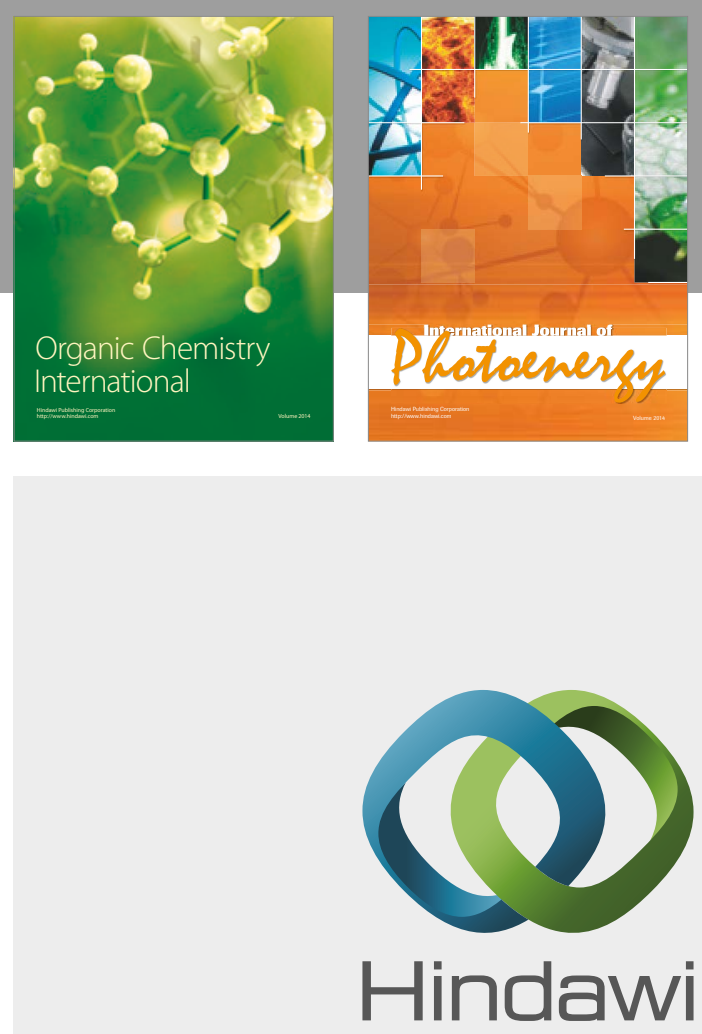

Submit your manuscripts at

https://www.hindawi.com

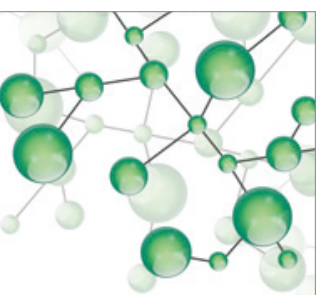

International Journal of

Inorganic Chemistry

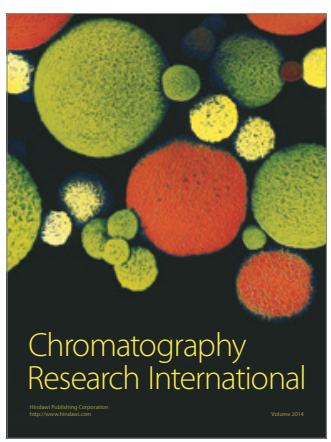

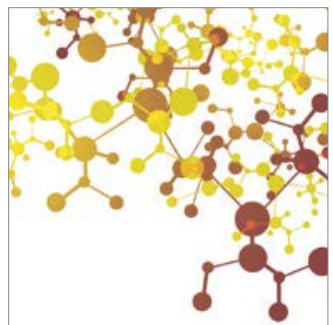

Applied Chemistry
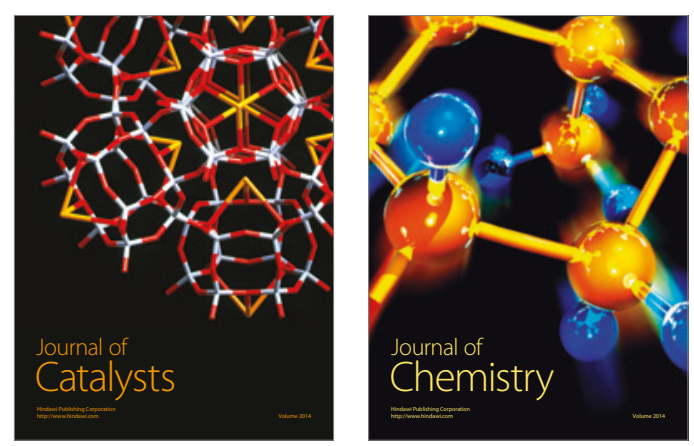
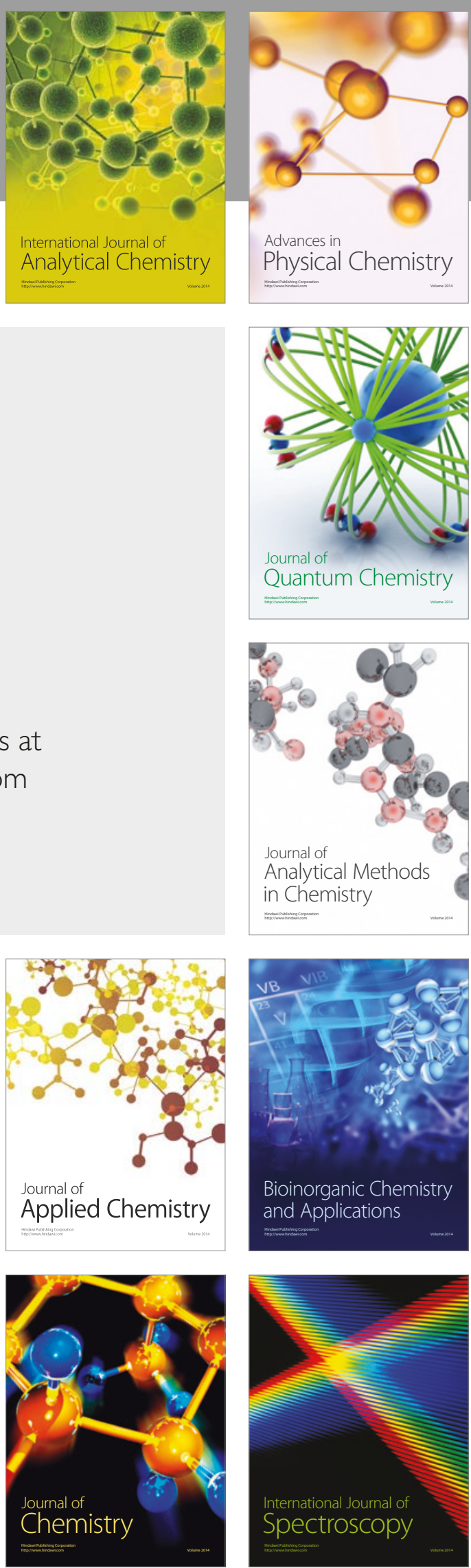